\title{
Avaliação da rigidez de misturas recicladas cimentadas: Abordagem elástica e viscoelásticas
}

\author{
Eduardo Pasche ${ }^{1}$, Luciano Pivoto Specht ${ }^{2}$, Mateus Camargo Tansky ${ }^{3}$, Nilo Cesar Consoli ${ }^{4}$ \\ 1UFRGS, Porto Alegre, RS, Brasil, dudipasche@gmail.com \\ 2UFSM, Santa Maria, RS, Brasil, luspecht@ufsm.br \\ 3UFSM, Santa Maria, RS, Brasil, tanskieng@gmail.com \\ 4UFRGS, Porto Alegre, RS, Brasil, consoli@ufrgs.br
}

\section{Recebido:}

11 de março de 2017

Aceito para publicação:

09 de outubro de 2017

Publicado:

30 de abril de 2018

Editor de área:

Francisco Thiago Aragão

\section{Palavras-chaves:}

Material fresado asfáltico,

Viscoelasticidade,

Rigidez.

\section{Keywords:}

Reclaimed Asphalt Pavement,

Viscoelastic,

Stiffness.

DOI:10.14295/transportes.v26i1.1342

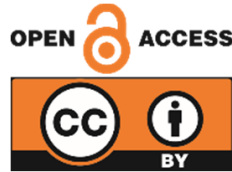

\begin{abstract}
RESUMO
Este artigo apresenta o estudo realizado com mistura de Reclaimed Asphalt Pavement (RAP) e pó de pedra com cimento Portland. Foram realizados ensaios para verificar o comportamento da mistura quanto à rigidez, de modo que possibilitou avaliar a influência do processo de cimentação e dos esforços de compactação, nas propriedades elásticas e viscoelásticas lineares da mistura cimentada. Os resultados indicaram que há um aumento da rigidez nos três teores de cimento estudados (3, 5 e 7\%), bem como um aumento nos pesos específicos aparentes secos $\left(2,0,2,1\right.$ e 2,2 g/ $\left.\mathrm{cm}^{3}\right)$. Pode-se - afirmar que estas misturas têm propriedades viscoelásticas provenientes da herança do ligante asfáltico presente no material fresado. Por fim, este trabalho demonstra que se deve ter cautela ao projetar pavimentos analisando apenas o material como puramente elástico, pois percebemos que há variação do módulo em relação à temperatura e à frequências de carregamento.
\end{abstract}

\section{ABSTRACT}

This paper presents a study of a mixture of Reclaimed Asphalt Pavement (RAP) with powdered rock and Portland cement. Tests were performed to verify the behavior of the mixture regarding the stiffness characteristics, so it was possible to evaluate the influence of cementation process and compaction efforts on the elastic and viscoelastic properties of the cemented mixture. The results showed that there is an increment in material stiffness for the three studied cement mixes (3, 5 and $7 \%)$ as well as an increment in the apparent specific dry weights $\left(2,0,2,1\right.$ and $\left.2,2 \mathrm{~g} / \mathrm{cm}^{3}\right)$. It can be demonstrated that these mixes have viscoelastic properties derived from asphalt binder present in the RAP. Lastly, this paper shows that should be careful with the designing pavements considering the material as only elastic, since it's clear the material stiffness dependency of temperature and load frequency.

\section{INTRODUÇÃO}

A implantação e manutenção de infraestrutura rodoviária é um dos fatores indutores do desenvolvimento econômico e social. Pavimentos asfálticos são a maioria no cenário da pavimentação brasileira, utilizando o concreto asfáltico tanto em obras de implantação quanto manutenção. Estima-se que mais de $90 \%$ das rodovias pavimentadas nacionais são de concreto asfáltico (ABEDA, 2011) e têm o objetivo de proporcionar aos usuários segurança e conforto durante o tráfego, além de durabilidade e resistência às cargas que lhes são impostas (Mendes e Marques, 2012).

Entretanto, diferente de outras obras de Engenharia, obras de infraestrutura rodoviária têm ciclo de vida curto, entre 6 e 30 anos, o que demanda atenção constante aos serviços de manutenção (conservação e reabilitação) (Papagiannakis e Massad, 2008; Medina e Motta, 2015; Pires et al., 2016).

Uma das formas para a correção dos defeitos dos pavimentos e o reestabelecimento de uma superfície de rolamento suave e segura é a restauração, sendo bastante empregada atualmente a fresagem do re- 
vestimento asfáltico antigo e recomposição com um novo. A etapa de fresagem consiste na operação de um corte ou desbaste do revestimento antigo, e produz grande quantidade de resíduos nas obras de restauração de rodovias, denominado de Reclaimed Asphalt Pavement (RAP) ou material fresado asfáltico ou somente fresado, que é a combinação de agregados e ligante envelhecido (DNIT, 2006b; Bonfim, 2016).

0 reaproveitamento deste material por meio de reciclagem tem sido alvo de inúmeras pesquisas no mundo. Na Europa e Estados Unidos o foco principal é o aproveitamento em misturas asfálticas a quente (Hajj et al., 2009; Daniel et al., 2013; Lo Presti et al., 2013; Mangiafico et al., 2013). No Brasil tem-se estudado o aproveitamento desse material em misturas asfálticas à quente ou à frio (Vasconcelos e Soares, 2003; Loreiro et al., 2004; Moreira e Soares, 2004; Vasconcelos e Soares, 2004; Soares et al., 2005; Silva et al., 2011; Araujo et al., 2013; Oliveira et al.,2013, Bessa et al., 2014; Lopes et al., 2015; Rocha Segundo et al., 2016) ou em camadas granulares do pavimento (Soares et al., 2000; Silva et al., 2013; Pasche et al., 2014; Bessa et al. , 2016a ; Bessa et al. , 2016b; Guatimosim et al., 2016; Hermes et al., 2016). Há possibilidade de se lançar mão de técnicas de estabilização para utilização do fresado a frio com adição de material virgem e/ou cimento e emulsão (Recasens et al.,2000; ARRA, 1997; Wright Jr., 2001; Dalla Rosa et al., 2015; Pires et al., 2016). Diversos autores (Hoyos et al., 2011; Puppala et al., 2011; Arulrajah et al., 2013; Pires et al., 2016), citam o material fresado reutilizado com sucesso como material de construção em bases e sub-bases rodoviárias, agregados de concreto asfáltico, taludes e aterros.

Conforme Hoy et al. (2016a, 2016b), a necessidade urgente de novas soluções ambientalmente amigáveis fez com que os pesquisadores explorassem novos materiais alternativos que reduzam o consumo de energia e as emissões de gases de efeito estufa. É fato que os custos crescentes dos materiais de construção, a redução da disponibilidade de materiais naturais e as novas exigências/limitações na construção de pavimentos rodoviários exigem novos materiais que associem bom desempenho, baixo custo e apelo ambiental.

Os mecanismos de degradação de um pavimento flexível, notadamente o trincamento por fadiga e as deformações permanentes excessivas, são resultantes da ação climática e do crescente aumento do tráfego, e dependem, principalmente das tensões e deformações atuantes na estrutura, sua compatibilização com os materiais empregados e suas leis de danificação (resistência aos esforços repetidos). Tanto a rigidez quanto as espessuras das camadas determinam a maneira como serão distribuídos os esforços oriundos do tráfego. Camadas estruturais mais rígidas e espessas elevam o grau de abertura do cone de tensões e reduzem os esforços solicitantes nas camadas subjacentes. Fica evidente que a rigidez do material é uma propriedade imprescindível para análise (Yoder e Witczak, 1975; Huang, 1993; Hunter, 1994; Di Benedetto e Corte, 2005; Balbo, 2007).

A consideração da deformabilidade em pavimentação não é algo novo, todavia, é fato que no Brasil misturas asfálticas e cimentadas são caracterizadas como materiais puramente elásticos lineares (que seguem a lei de Hooke) (DNIT, 2006a; Specht et al., 2006; Bernucci et al., 2010; DNIT, 2010b; ABNT, 2011).

Para materiais cimentados, como solo-cimento ou BGTC, tal consideração parece razoável, porém quando se utilizam materiais asfálticos na composição das misturas é temerário tal abordagem dada a natureza viscoelástica do ligante asfáltico. Tal abordagem viscoelástica (propriedades dependentes da frequência de carregamento e da temperatura) já é de uso corrente no exterior para ligantes e misturas asfálticas (Di Benedetto et al., 2001; Di Benedetto e Corte, 2005; Hornych et al., 2013, Specht et al., 2017). Alguns trabalhos realizados já dão tal enfoque para misturas recicladas com cimento (Bilodeau et al. 2011; Dong e Huang, 2013; Nguyen et al., 2016, Consoli et al., 2017). Fica então a questão: Para misturas contendo RAP estabilizado com cimento, qual a abordagem adequada de caracterização de rigidez? elástica ou viscoelástica?

Neste contexto, o objetivo deste trabalho é avaliar se há influência da cimentação e da densidade (compactação) nas propriedades elásticas e viscoelásticas lineares em misturas cimentadas de RAP e pó de pedra. 


\section{DESENVOLVIMENTO DA PESQUISA}

O programa experimental foi realizado em segmentos distintos. Em primeiro lugar, as propriedades do RAP e do pó de pedra foram determinadas. Em seguida, foram estabelecidas curvas de compactação considerando três energias distintas (Normal, Intermediária e Modificada). Finalmente, foram feitos ensaios para determinar o módulo de resiliência e o módulo complexo (módulo dinâmico e ângulo de fase). Este último utiliza diversas temperaturas e frequências de aplicação de carga durante o ensaio.

\subsection{Materiais}

O RAP é proveniente da fresagem da BR 290/RS, trecho concedido à Triunfo Concepa (Concessionária da Rodovia Osório Porto Alegre) no município de Porto Alegre/RS. O percentual de ligante asfáltico presente no RAP foi de 5,0\%, determinado conforme o ensaio de extração de betume segundo a norma DNER-ME 053 (1994). A massa específica dos agregados do RAP ( $\gamma \mathrm{s}$ ) foi de $2,517 \mathrm{~g} / \mathrm{cm}^{3}$, conforme a NBR NM 52 (2009a) e a NBR NM 53 (2009b), enquanto que a massa específica dos RAP ( $\left.\gamma_{S_{R A P}}\right)$ foi de $2,579 \mathrm{~g} / \mathrm{cm}^{3}$, determinada com a metodologia RICE (NBR 15619, 2016). Os resultados da determinação da distribuição granulométrica de acordo com a NBR NM 248 (2003), está apresentada na Tabela 1 e na Figura 1. 0 pó de pedra (PDP) foi coletado diretamente na unidade de britagem de uma pedreira de rocha Vulcânica/Basáltica, no Município de Santo Antônio da Patrulha/RS. A distribuição granulométrica está apresentada na Figura 1. A massa específica deste material $\left(\gamma_{\mathrm{S}} \mathrm{PDP}\right)$ é $2,779 \mathrm{~g} / \mathrm{cm}^{3}$, conforme NBR NM 52 (2009a).

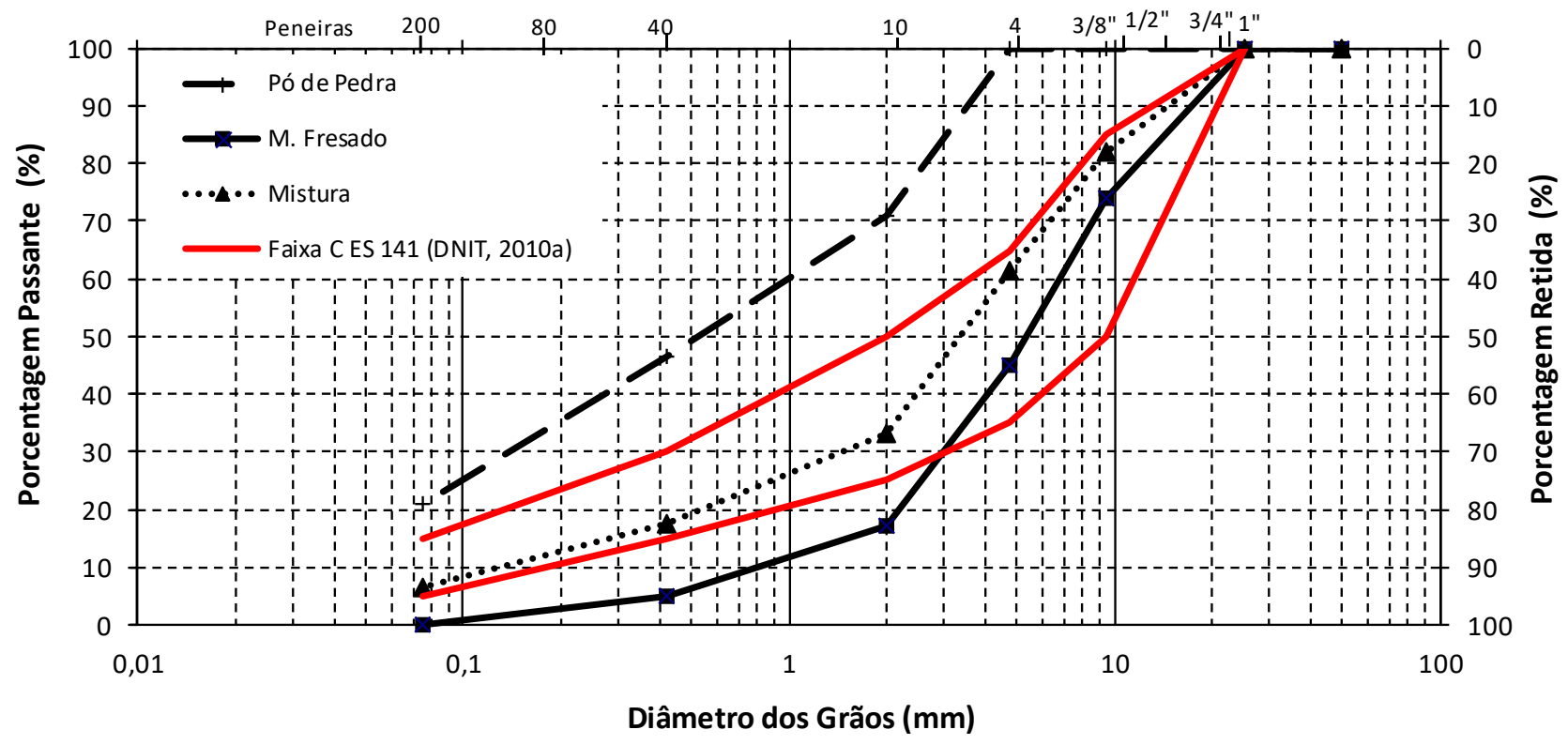

Figura 1: Granulometria dos agregados utilizados

O cimento utilizado na pesquisa foi o CP V- ARI - Cimento Portland de Alta Resistência Inicial produzido pela Cauê. A utilização do cimento nesta pesquisa foi determinada para que pudesse ser realizada estabilização química das misturas, com o emprego de diferentes teores para verificar a influência da cimentação no comportamento mecânico. A massa específica deste material $\left(\gamma_{\mathrm{S}_{\mathrm{CP}}}\right)$ é $3,151 \mathrm{~g} / \mathrm{cm}^{3}$, conforme NBR NM 23 (2001); os ensaios de caracterização realizados no cimento (com exceção da Finura Blaine) estão apresentados na Tabela 1. 
Tabela 1: Características e propriedades do cimento

\begin{tabular}{lllll}
\hline Características e Propriedades & Unidade & Resultados & Limites - NBR 5733 (1991) \\
\hline \multirow{2}{*}{ Finura } & Retido \#200 & $\%$ & 1,2 & $\leq 6$ \\
& Área Específica - Blaine & $\mathrm{m}^{2} / \mathrm{kg}$ & 533 & $\geq 300$ \\
\hline \multirow{2}{*}{ Tempo de Pega } & Início & Minutos & 225 & $\geq 60$ \\
& Fim & Minutos & 305 & $\leq 600$ \\
\hline \multirow{2}{*}{ Resistência } & 1 dia de cura & MPa & 26,4 & $\geq 14$ \\
\multirow{A}{*}{ Compressão } & 3 dias de cura & $\mathrm{MPa}$ & 35,2 & $\geq 24$ \\
& 7 dias de cura & $\mathrm{MPa}$ & 46,4 & $\geq 34$ \\
\hline
\end{tabular}

\subsection{Ensaios}

\subsubsection{Moldagem e cura das amostras}

Todas as amostras foram preparadas misturando as quantidades necessárias de RAP, PDP, CP e água. As quantidades de RAP e PDP foram de 70/30 (curva de ajuste apresentada na Figura 1), como já estudado em outras pesquisas (Specht et al. 2013; Pasche et al., 2014, Hermes et al., 2016), e os teores de cimento (TC) foram de 3, 5 e 7\% do peso da amostra. Os resultados da compactação para energia Normal, Intermediaria e Modificada estão apresentadas na Figura 2. Com a compactação foram definidas três massas específicas secas $\left(2,0,2,1\right.$ e $\left.2,2 \mathrm{~g} / \mathrm{cm}^{3}\right)$, com o teor de umidade de $8 \%$ para serem investigadas, conforme indicado na Figura 2.

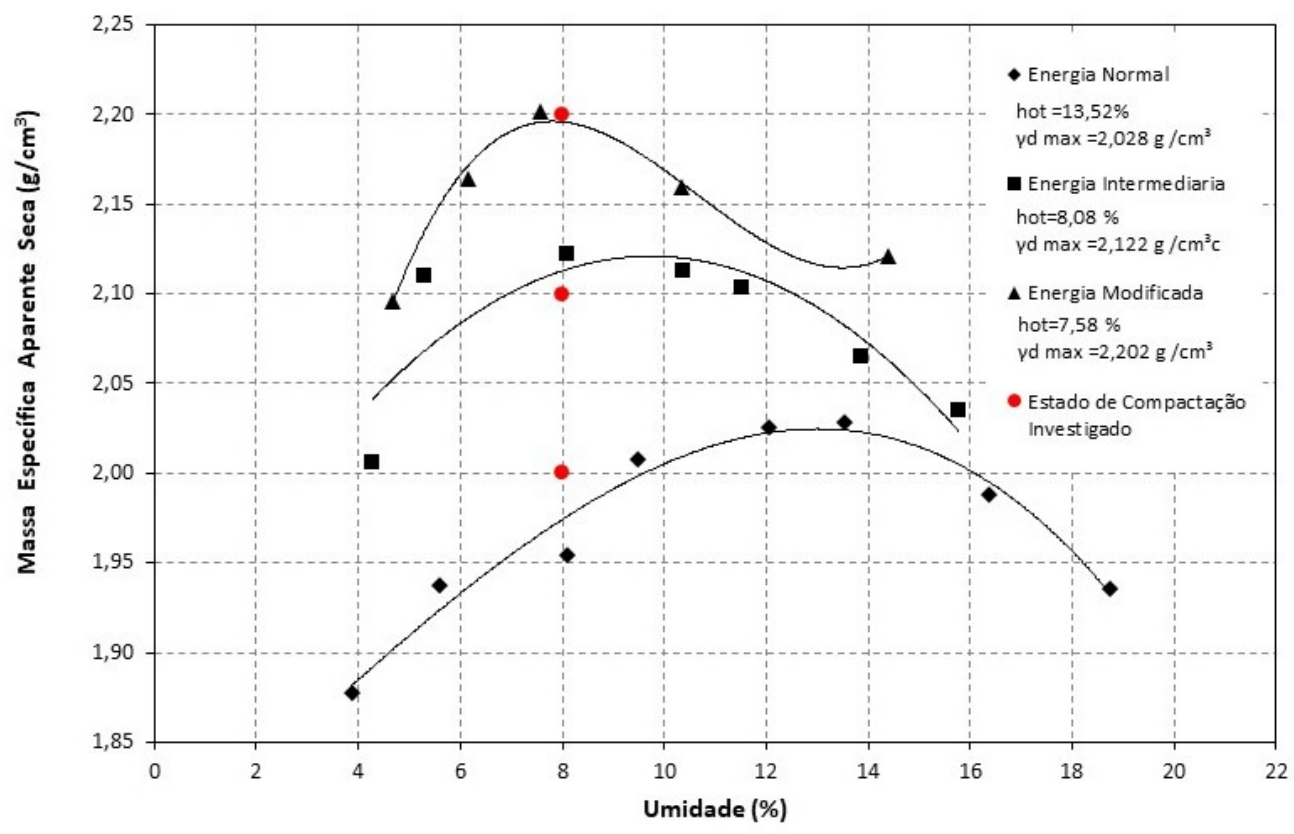

Figura 2: Curvas de compactação da mistura de $70 \%$ de RAP de $30 \%$ pó de pedra

Para a preparação das amostras foram determinadas as massas secas de RAP, PDP e CP; e misturadas até obter-se um material uniforme. A seguir, adicionou-se água (para atingir o teor de umidade pretendido), prosseguindo o processo de misturação até a criação de um material perfeitamente homogêneo. 0 corpo de prova foi então compactado estaticamente em camadas dentro de um molde tripartido cilíndrico, de modo que cada camada atingisse a massa específica indicada. 0 topo de cada camada foi ligeiramente escarificado.

Após o processo de moldagem, os corpos de prova eram extraídos do molde e, então, determinados sua massa, diâmetro e altura com precisões de $0,01 \mathrm{~g}$ e $0,1 \mathrm{~mm}$. As amostras foram curadas por 28 dias a $21^{\circ} \pm 2{ }^{\circ} \mathrm{C}$ e umidade relativa acima de $95 \%$. 


\subsubsection{Módulo de Resiliência}

Os procedimentos para o ensaio módulo de resiliência (MR) se baseia na DNIT-ME 125 (2010b) e na AASHTO T 242 (2011). Foram moldados um total de 27 corpos de prova, com dimensão aproximada de $6,50 \mathrm{~cm}$ de altura e $10 \mathrm{~cm}$ de diâmetro. Os corpos de prova foram ensaiados no Laboratório de Materiais de Construção Civil, da Universidade Federal de Santa Maria. O equipamento utilizado foi uma prensa universal UTM-25 (IPC Global), que é composta por um pistão que proporciona um carregamento repetido pulsante com o auxílio de um dispositivo hidráulico, acoplado a um regulador de tempo e frequência. Os ensaios são realizados em uma câmara com temperatura controlada.

O MR é a relação entre a tensão de tração aplicada $(\sigma)$ repetidamente no plano diametral vertical de uma amostra cilíndrica e a deformação específica recuperável $(\varepsilon)$. A aplicação de carga é semissenoidal, por se aproximar da forma de carregamento correspondente à passagem de roda. 0 tempo de duração de aplicação total de carga é de 0,1 s e o repouso de 0 ,9s a cada 1s. Para a execução do ensaio, o carregamento utilizado deve ser suficiente para deformar a amostra sem causar dano, ou seja, manter o material no domínio das pequenas deformações. 0 coeficiente Poisson empregado para o cálculo foi 0,30.

\subsubsection{Módulo Complexo}

0 ensaio de módulo complexo $\left(\mathrm{E}^{*}\right)$ pode ser usado para determinar tanto as características elásticas quanto as propriedades viscoelásticas do material (Chistensen, 1982), isto é, esse ensaio determina o ângulo de fase $(\delta)$ e o módulo dinâmico $\left(\left|E^{*}\right|\right)$. Para isso, foram moldadas 16 amostras, com dimensões 10x15cm seguindo as recomendações da norma AASHTO TP 79 (2015). Para esse ensaio foram utilizadas cinco temperaturas $\left(-10,4,21,37\right.$ e $\left.54 \mathrm{C}^{\circ}\right)$ e dez frequências $(0,01,0,1,0,2,0,5,1,2,5,10,20$ e 25 $\mathrm{Hz})$.

O procedimento é repetido para diferentes temperaturas e frequências de carregamento com o intuito de construir uma curva mestra que incorpore os efeitos destas variáveis (Francken e Partl, 1996). São geradas duas curvas mestras: uma de ângulo de fase que proporciona a verificação do comportamento viscoso do material em diferentes temperaturas e frequências, e uma de módulo dinâmico que permite a análise da variação do módulo em diferentes temperaturas e frequências.

Para a interpretação e modelagem dos resultados foi utilizado o modelo 2S2P1D (2 Springs, 2 Parabolic and 1 Dashpot), desenvolvido por Di Benedetto e Olard (2003) e Di Benedetto et al. (2004). 0 modelo serve para descrever propriedades viscoelásticas lineares de ligantes e misturas asfálticas. 0 modelo 2S2P1D possui parâmetros de calibração para representação correta do comportamento do material em termos de módulo, ângulo de fase e coeficiente de Poisson (este não utilizado neste trabalho), para diferentes temperaturas e frequências. 0 módulo é calculado pela Equação 1, e a Figura 3 apresenta no plano Cole-Cole as variáveis do modelo.

$$
\mathrm{E} *(\omega)=\mathrm{E} 00 \frac{\mathrm{E} 0-\mathrm{E} 00}{1+\delta(\mathrm{j} \omega \tau)-\mathrm{k}+(\mathrm{j} \omega \tau)-\mathrm{h}+(\mathrm{j} \omega \beta \tau)-1}
$$

Onde:

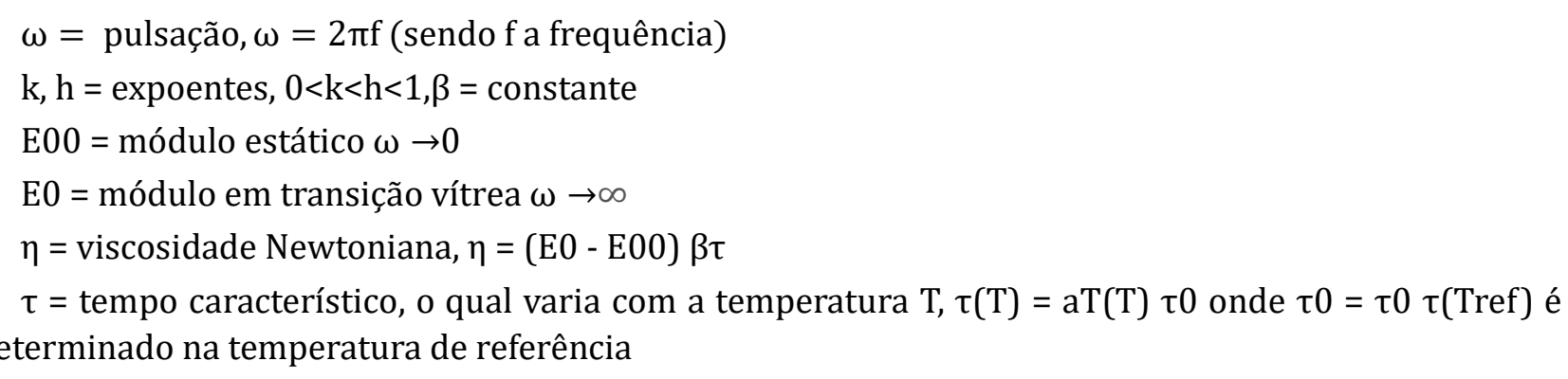




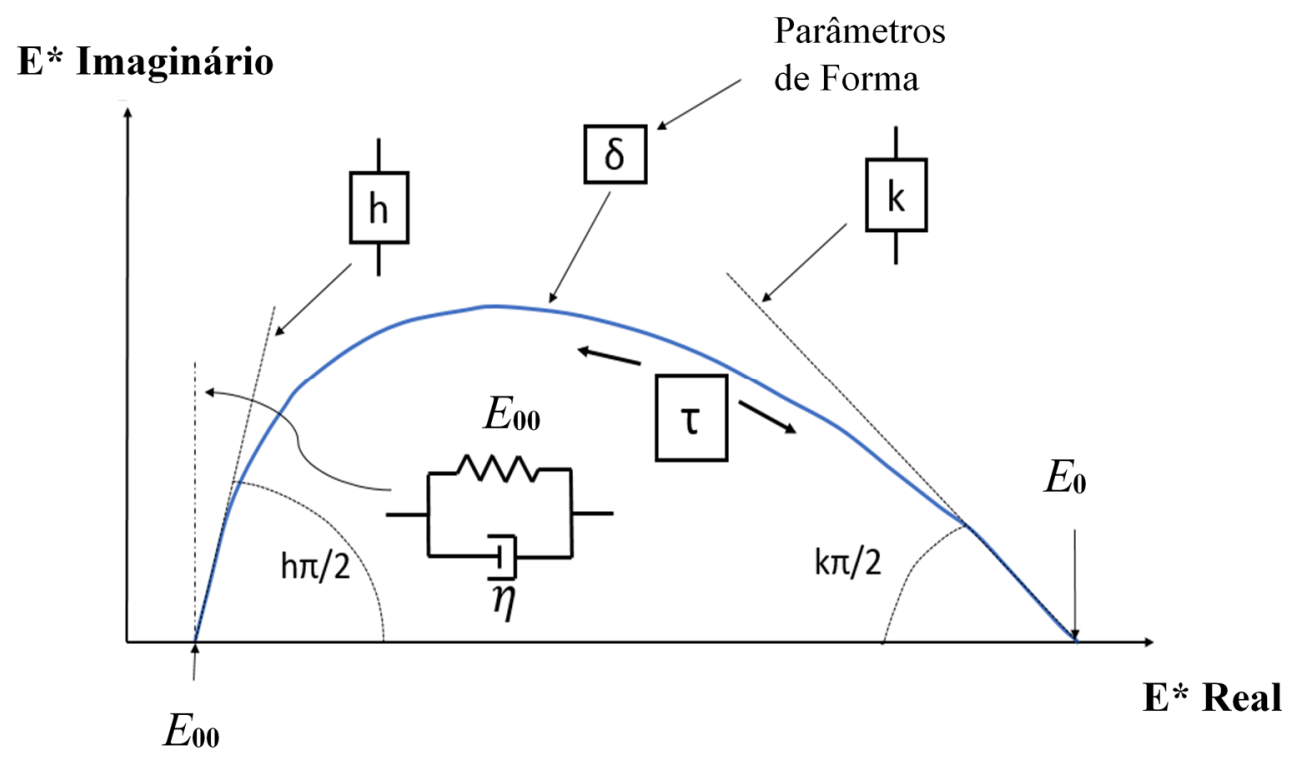

Figura 3: Influência dos parâmetros associados aos elementos físicos do modelo 2S2P1D Fonte: Di Benedetto et al. (2004)

\section{RESULTADOS}

\subsection{Módulo de resiliência}

Na Tabela 2, é exposto um resumo dos valores de MR para as misturas estabilizadas com diferentes teores de cimento (TC) e massas específicas. Na Figura 4 são apresentadas retas da variação do módulo de resiliência em função do teor de cimento. Cada reta, isoladamente, possui a mesma massa específica aparente seca e todos os pontos têm o mesmo teor de umidade $(\mathrm{h}=8 \%)$. Cada ponto corresponde à média do módulo de três corpos de prova moldados, bem com a barra de erro o desvio padrão dos resultados. Pode-se observar que a quantidade de cimento tem um grande efeito sobre o módulo de resiliência. Mesmo pequenas adições de cimento são suficientes para gerar importantes incrementos de rigidez. Também se observou que o módulo tem um crescimento linear em relação ao aumento da quantidade de cimento, para os teores estudados. Além disso, também foi verificado que para um mesmo teor de cimento, aumentando a energia de compactação, aumenta a rigidez de maneira análoga a um determinado teor de cimento. Fica claro que energias mais altas possibilitam um intertravamento maior dos agregados, redução do volume de vazios e maior efetividade do mástique cimentante.

Tabela 2: Resultados médios do Módulo de Resiliência

\begin{tabular}{|c|c|c|c|}
\hline ps $\left(\mathrm{g} / \mathrm{cm}^{3}\right)$ & TC (\%) & MR (MPa) & Desvio Padrão \\
\hline \multirow{3}{*}{2,0} & 3 & 5409 & 779 \\
\hline & 5 & 7301 & 1491 \\
\hline & 7 & 8393 & 1339 \\
\hline \multirow{3}{*}{2,1} & 3 & 6704 & 1661 \\
\hline & 5 & 8508 & 315 \\
\hline & 7 & 9704 & 13 \\
\hline \multirow{3}{*}{2,2} & 3 & 7534 & 732 \\
\hline & 5 & 10006 & 44 \\
\hline & 7 & 11764 & 421 \\
\hline
\end{tabular}

Também na Figura 4 são plotados os valores da normal do módulo complexo para a mesma frequência (10hz) e temperatura $\left(25^{\circ} \mathrm{C}\right)$ do ensaio de MR e nota-se que os valores são menores, sugerindo valores medidos à compressão menores que valores à tração, mas seguem a mesma tendência, a não ser pela tendência de agrupamento para o maior teor de cimento, o que pode indicar que, para altos teores de 
cimento a densidade torna-se menos importante. Para se ter uma ideia da importância da cimentação, podemos comparar os valores obtidos com os de Hermes et al. (2016) que retro analisaram uma pavimento executado com as mesmas proporções de RAP e pó de pedra deste trabalho e obtiveram valores de módulo entre 150 e $300 \mathrm{MPa}$, muito inferiores aos aqui apresentados. Os valores encontrados são compatíveis com materiais cimentados (solo-cimento, concreto asfáltico, brita graduada tratada com cimento, etc...).

Foram realizadas análises estatísticas tipo teste de significância (p-valor é menor que 5\%) e Análises de Regressão Linear Múltiplas e ficou patente que tanto a densidade aparente quanto o teor de cimento têm influência nas variáveis MR e $\left|E^{*}\right|$. Pelos coeficientes do modelo normalizados, verificou-se que a influência do TC é aproximadamente $20 \%$ maior que da densidade para ambas as variáveis independentes.

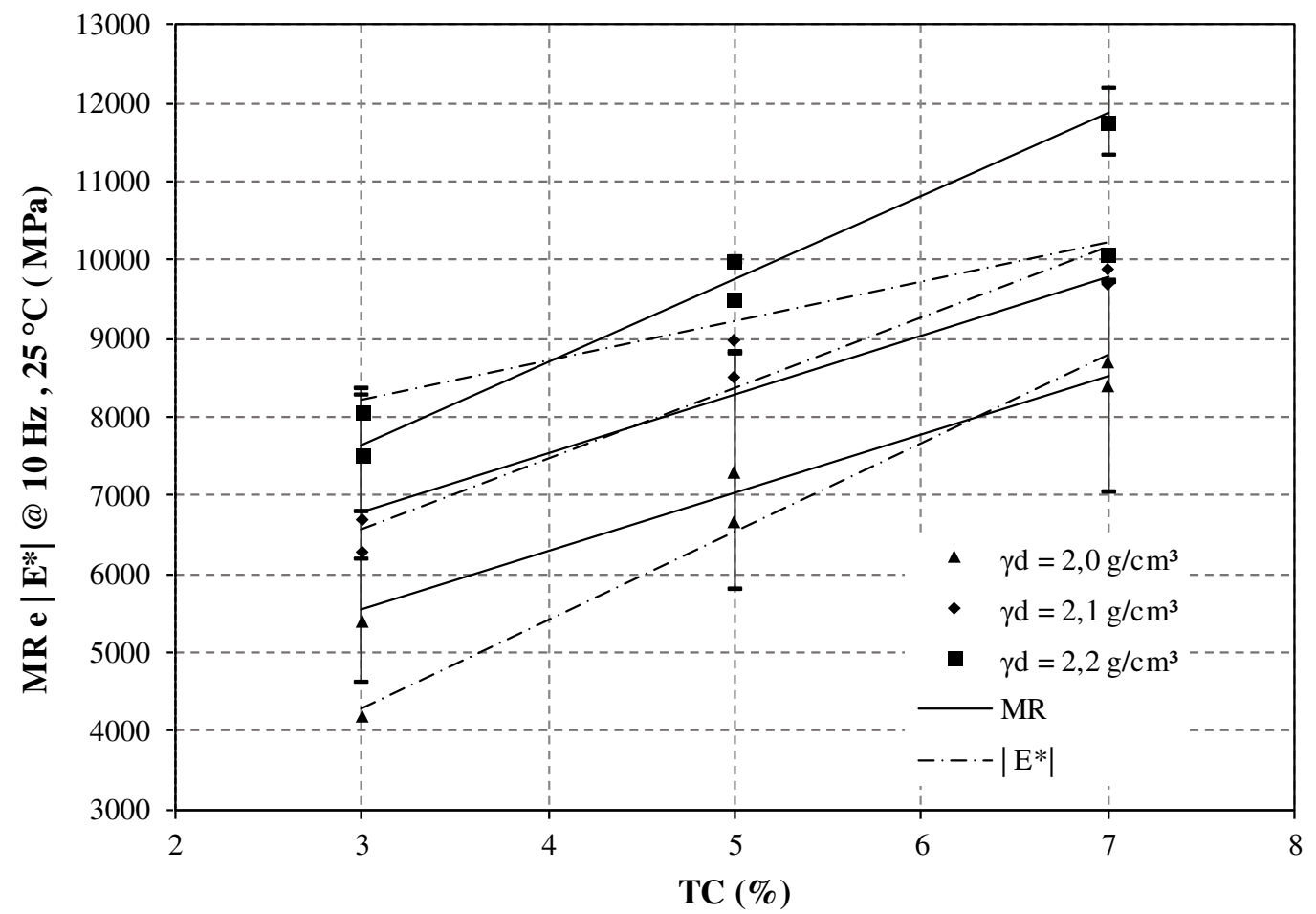

Figura 4: Variação do $M R$ e do $\left|E^{*}\right|$ a $25^{\circ} \mathrm{C}$ em relação ao teor de cimento (TC)

\subsection{Módulo Complexo}

Os dados de módulo dinâmico foram, inicialmente, plotados junto a Figura 4, na mesma temperatura e frequência, para comparar com o MR, mesmo sabendo que são medidas diferentes do ponto de vista da homogeneidade e estado de tensões. Não é possível estabelecer uma relação única entre MR e $\left|E^{*}\right|$. Por vezes o MR é maior, por vezes o $\left|E^{*}\right|$ é maior. Os resultados de módulo dinâmico e MR, para a massa específica de $2,1 \mathrm{~g} / \mathrm{cm}^{3}$, parecem ter uma boa concordância, o que não ocorre para as demais. Além disso, os valores de módulo dinâmico parecem tender a um valor unívoco à medida que se aumenta o teor de cimento, ou seja, independem da densidade.

Os resultados dos ensaios de módulo complexo são expressos em gráficos no espaço Cole-Cole, Diagrama de Black, Curvas mestras de módulo dinâmico e ângulo de fase, a fim de representar e compreender o comportamento viscoelástico das misturas. A Figura 5, apresenta os resultados no espaço ColeCole, com a média de duas amostras ensaiadas e os resultados obtidos através da modelagem 2S2P1D (parâmetros ajustados na Tabela 3). 


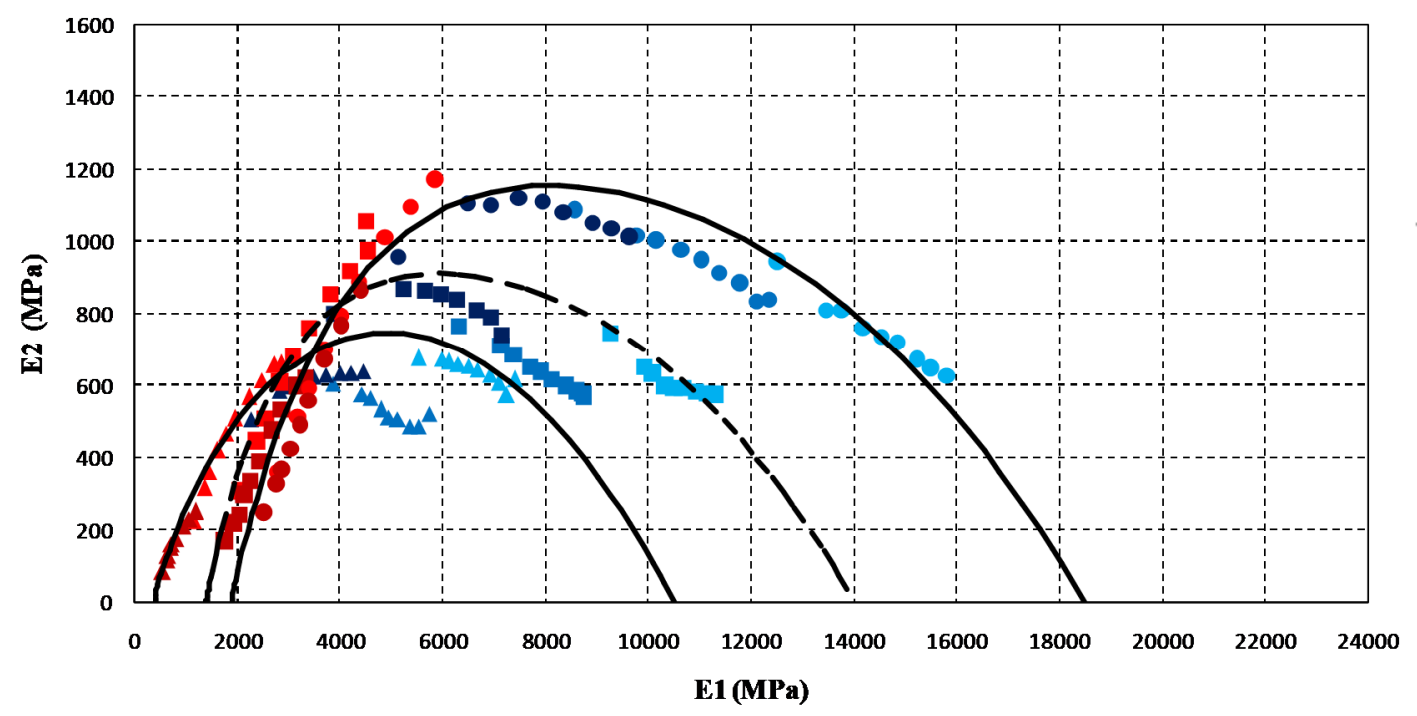

- $\mathrm{TC}=3 \%$
- $\mathrm{TC}=5 \%$
- $\mathrm{TC}=7 \%$

$-3 \% 2 \mathrm{~S} 2 \mathrm{P} 1 \mathrm{D}$

$--5 \% 2 \mathrm{~S} 2 \mathrm{P} 1 \mathrm{D}$

$7 \% 2 \mathrm{~S} 2 \mathrm{P} 1 \mathrm{D}$

Temp.

$--10^{\circ} \mathrm{C}$

- $4^{\circ} \mathrm{C}$

- $21^{\circ} \mathrm{C}$

- $37^{\circ} \mathrm{C}$

- $54^{\circ} \mathrm{C}$

(a)

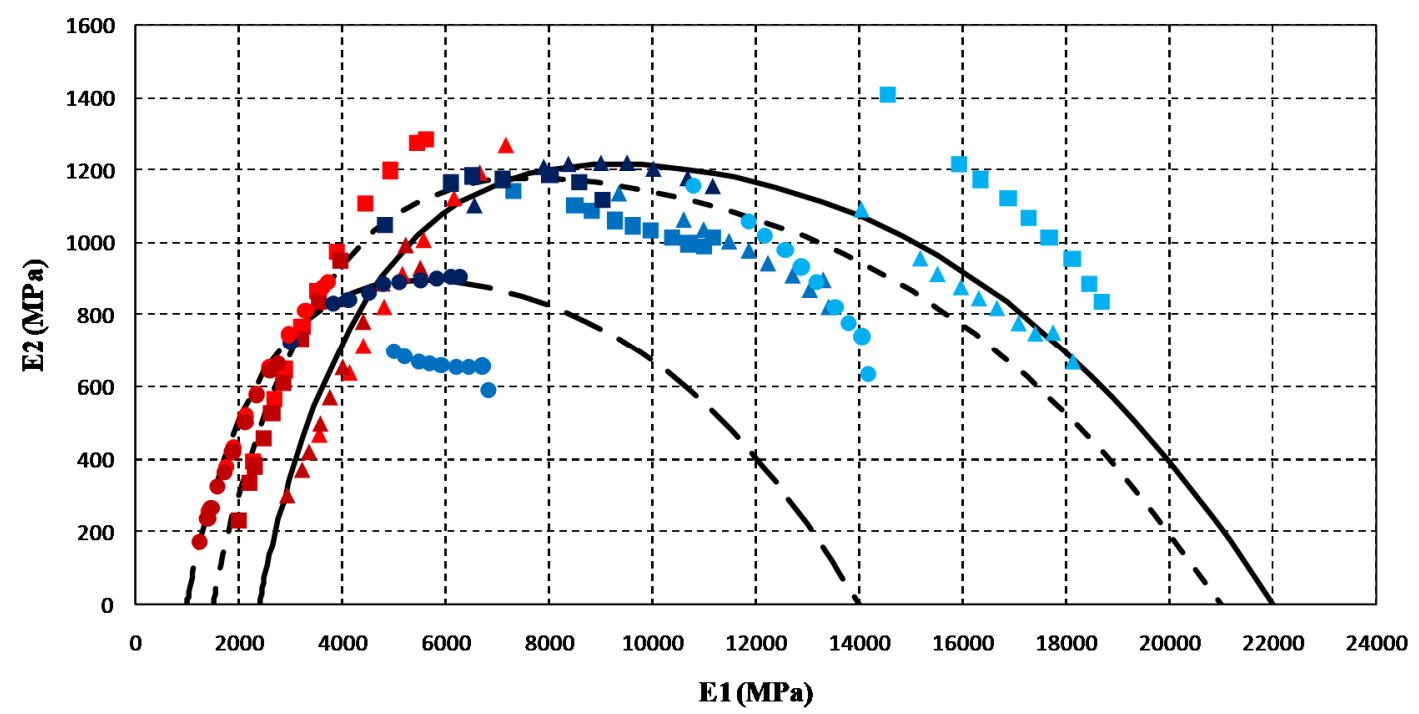

A $\mathrm{TC}=3 \%$

- $\mathrm{TC}=5 \%$

- $\mathrm{TC}=7 \%$

$--3 \% 2 \mathrm{~S} 2 \mathrm{P} 1 \mathrm{D}$

- - $5 \% 2 \mathrm{~S} 2 \mathrm{P} 1 \mathrm{D}$

$7 \% 2$ S2P1D

Temp.

$--10^{\circ} \mathrm{C}$

$-4{ }^{\circ} \mathrm{C}$

- $21^{\circ} \mathrm{C}$

- $37^{\circ} \mathrm{C}$

(b)

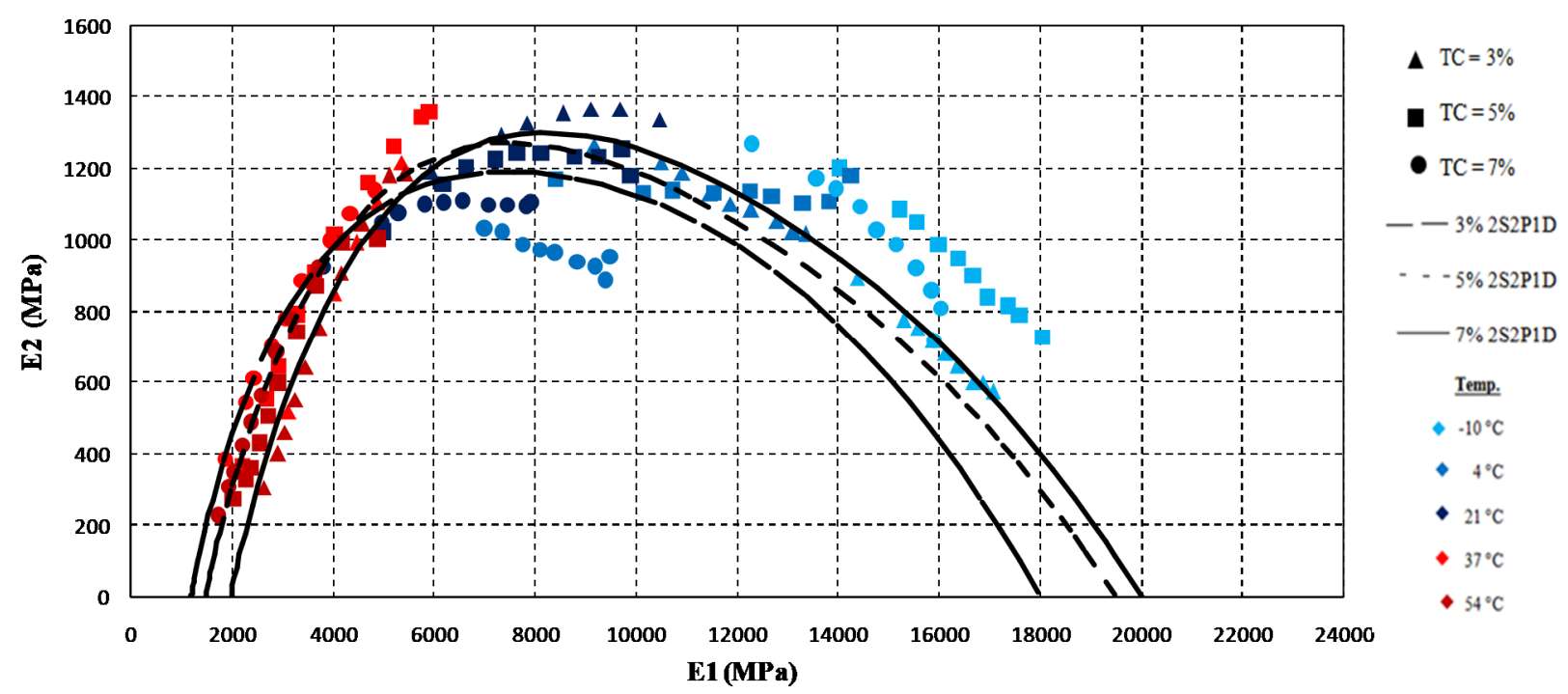

(c)

Figura 5: Diagrama Cole-Cole: a) $\gamma_{d}=2,0 \mathrm{~g} / \mathrm{cm}^{3}$; b) $\gamma_{d}=2,1 \mathrm{~g} / \mathrm{cm}^{3}$; c) $\gamma_{d}=2,2 \mathrm{~g} / \mathrm{cm}^{3}$ 
Tabela 3: Parâmetros do modelo 2S2P1D e valores de C1 e C2 para as misturas

\begin{tabular}{|c|c|c|c|c|c|c|c|c|c|c|}
\hline \multirow{2}{*}{\multicolumn{2}{|c|}{ Mistura }} & \multicolumn{7}{|c|}{$\mathrm{E}^{*}$} & \multicolumn{2}{|c|}{ WLF } \\
\hline & & \multirow{2}{*}{$\begin{array}{c}\mathrm{E}_{00} \text { (MPa) } \\
400\end{array}$} & \multirow{2}{*}{$\begin{array}{c}\mathrm{E}_{\mathbf{0}} \text { (MPa) } \\
10500\end{array}$} & \multirow{2}{*}{$\begin{array}{c}\frac{\mathbf{k}}{0,17} \\
0,17\end{array}$} & \multirow{2}{*}{$\frac{\mathbf{h}}{0,38}$} & \multirow{2}{*}{$\frac{\text { d }}{3,00}$} & \multirow{2}{*}{$\frac{t_{E}(s)}{1}$} & \multirow{2}{*}{$\frac{\text { b }}{5000}$} & \multirow{2}{*}{$\begin{array}{l}\text { C1 } \\
40\end{array}$} & \multirow{2}{*}{$\frac{\mathrm{C2}\left({ }^{\circ} \mathrm{C}\right)}{299}$} \\
\hline 2,0 & $3 \%$ & & & & & & & & & \\
\hline 2,0 & $5 \%$ & 1400 & 14000 & 0,16 & 0,45 & 2,40 & 1 & 7000 & 40 & 299 \\
\hline 2,0 & $7 \%$ & 1900 & 18500 & 0,15 & 0,42 & 2,40 & 1 & 7000 & 40 & 299 \\
\hline 2,1 & $3 \%$ & 1000 & 14000 & 0,15 & 0,45 & 2,50 & 1 & 7000 & 40 & 299 \\
\hline 2,1 & $5 \%$ & 1500 & 21000 & 0,13 & 0,42 & 2,50 & 1 & 7000 & 40 & 299 \\
\hline 2,1 & $7 \%$ & 2400 & 22000 & 0,14 & 0,42 & 2,60 & 1 & 7000 & 40 & 299 \\
\hline 2,2 & $3 \%$ & 1200 & 18000 & 0,16 & 0,44 & 2,50 & 1 & 7000 & 40 & 299 \\
\hline 2,2 & $5 \%$ & 1500 & 19500 & 0,14 & 0,40 & 1,90 & 1 & 7000 & 40 & 299 \\
\hline 2,2 & $7 \%$ & 2000 & 20000 & 0,14 & 0,40 & 1,90 & 1 & 7000 & 40 & 299 \\
\hline
\end{tabular}

Mediante as Figuras 5: a, b e c, pode se observar que os dados tendem a formar curvas de formato semicírculo, o qual era esperado para a Cole-Cole, porém nota-se que valores de E1 das misturas tendem a valores mais altos do que normalmente ocorre para misturas asfálticas, isso em razão da cimentação causada pelo cimento Portland. É possível notar também que as misturas com 3\% de cimento apresentam os menores valores de $\mathrm{E} 2$, no geral, quando comparadas às misturas com os maiores teores. Isto indica que as misturas com elevado teor de cimento apresentam uma maior mobilização do esqueleto mineral, bem como menor dissipação de energia.

Fica claro que a compactação (aumento da massa específica) das misturas aumentou a aproximação das curvas, e isso se dá, pela aproximação dos grãos no esqueleto mineral, tornando assim o corpo de prova mais rígido e mais suscetível à dissipação de energia, demonstrado pelo maior valor de E2.

A Figura 6 apresenta a representação gráfica dos resultados no Diagrama Black para os resultados experimentais e por meio da modelagem 2S2P1D. Percebe-se que a região dos módulos, onde ocorre o acréscimo do ângulo de fase, é identificada para condições de temperatura elevada a partir de $37^{\circ} \mathrm{C}$, e há um decréscimo a partir dos $54^{\circ} \mathrm{C}$. Isso se dá em virtude de que o ligante presente no material fresado começa a amolecer, perdendo assim sua característica cimentante, havendo assim uma mobilização das tensões no esqueleto mineral, que é essencialmente elástico.

Ainda, observa-se que as misturas com um teor mais baixo de cimento, apresentam os maiores valores de ângulo de fase, ou seja, essas misturas trazem uma parcela viscosa mais importante com relação à parcela elástica. A partir disso, é possível inferir que estas misturas apresentariam, em campo, mais deformações plásticas quando comparadas às demais misturas.

A Figura 7 apresenta a comparação de todas as curvas mestras de módulo das misturas e de misturas tipo concreto asfáltico. É possível verificar que o módulo dinâmico cresce em função da frequência. 0 menor valor verificado para o módulo dinâmico é encontrado nas temperaturas mais altas, o que explica o formato da curva mestra. Pode se notar que, nessas temperaturas as misturas da pesquisa obtêm um módulo mais elevado do que as misturas asfálticas dos outros autores, em virtude da cimentação do material.

A Figura 8 apresenta a curva mestra do ângulo de fase para todas as misturas. É possível verificar que as misturas asfálticas têm os maiores ângulos de fase em razão da presença do ligante asfáltico, porém, em altas frequências (que fogem a aplicações práticas), tendem a um valor único, pois tanto o ligante asfáltico novo quanto o presente no material fresado ficam tão elásticos que a manifestação viscoelástica é mínima.

Vale mencionar, que mesmo com variações menores de módulo dinâmico e ângulo de fase, e que este material quando empregado em base, estará menos sujeito a variações de temperatura e frequência de carga, a variação da rigidez chega a dez vezes para o domínio estudado, o que impactará de sobremaneira a análise estrutural de pavimentos. 

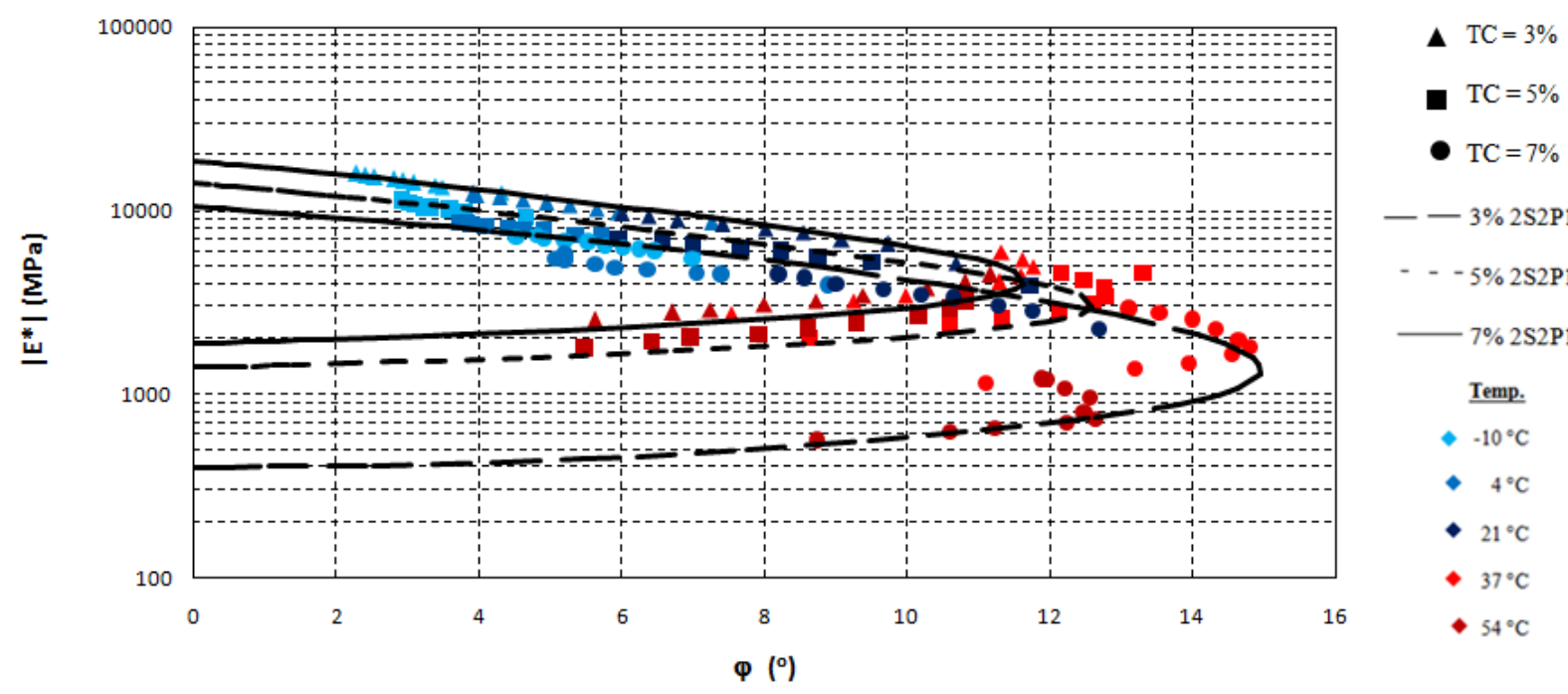

$-3 \% 2 \mathrm{~S} 2 \mathrm{P} 1 \mathrm{D}$

$-5 \% 2 \mathrm{~S} 2 \mathrm{P} 1 \mathrm{D}$

$-7 \% 2 \mathrm{~S} 2 \mathrm{P} 1 \mathrm{D}$

Temp.

$-10^{\circ} \mathrm{C}$

$-4^{\circ} \mathrm{C}$

- $21^{\circ} \mathrm{C}$

- $37^{\circ} \mathrm{C}$

$-54^{\circ} \mathrm{C}$

(a)

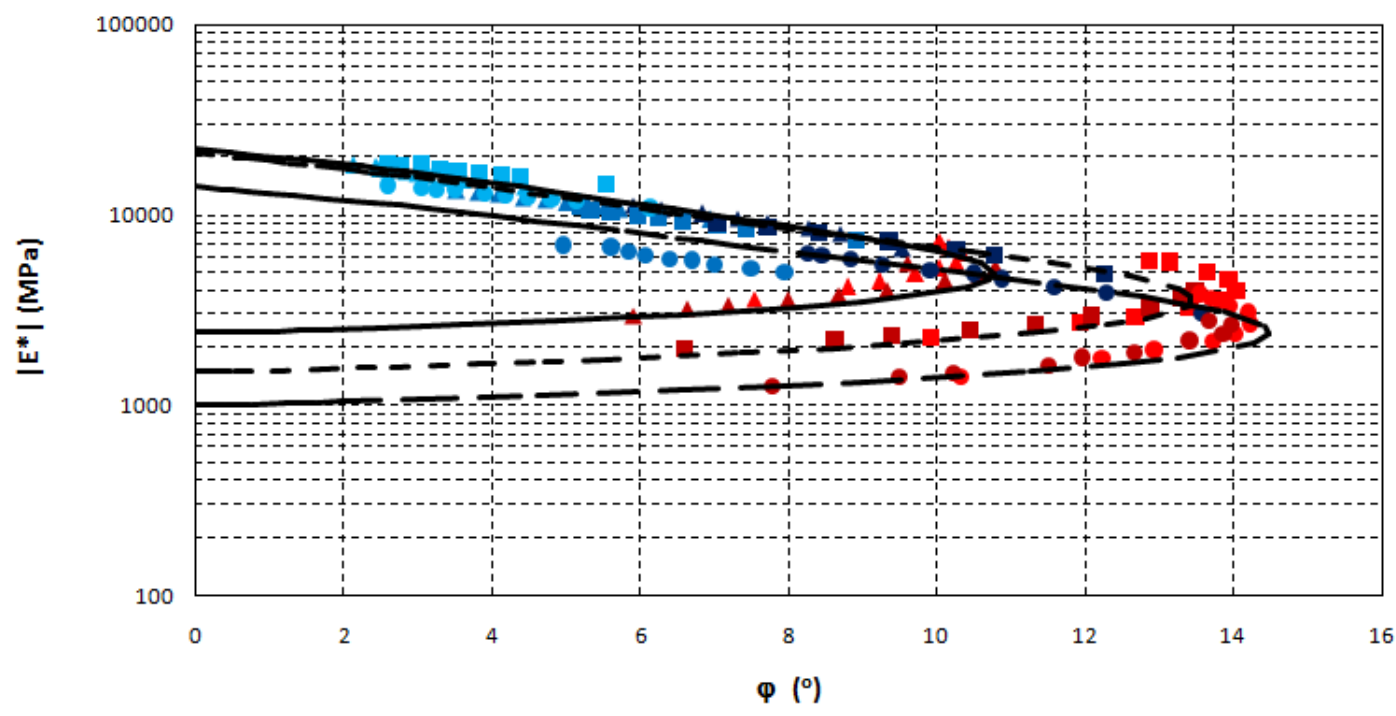

$$
\begin{aligned}
& \text { - } \mathrm{TC}=3 \% \\
& \text { - } \mathrm{TC}=5 \% \\
& \text { - } \mathrm{TC}=7 \% \\
& -3 \% 2 \mathrm{~S} 2 \mathrm{P} 1 \mathrm{D} \\
& \text { - - } 5 \% 2 \mathrm{~S} 2 \mathrm{P} 1 \mathrm{D} \\
& -7 \% 2 \mathrm{~S} 2 \mathrm{P} 1 \mathrm{D} \\
& \text { Temp. } \\
& -10^{\circ} \mathrm{C} \\
& -4^{\circ} \mathrm{C} \\
& \text { - } 21^{\circ} \mathrm{C} \\
& \text { - } 37^{\circ} \mathrm{C} \\
& \text { - } 54^{\circ} \mathrm{C}
\end{aligned}
$$

(b)

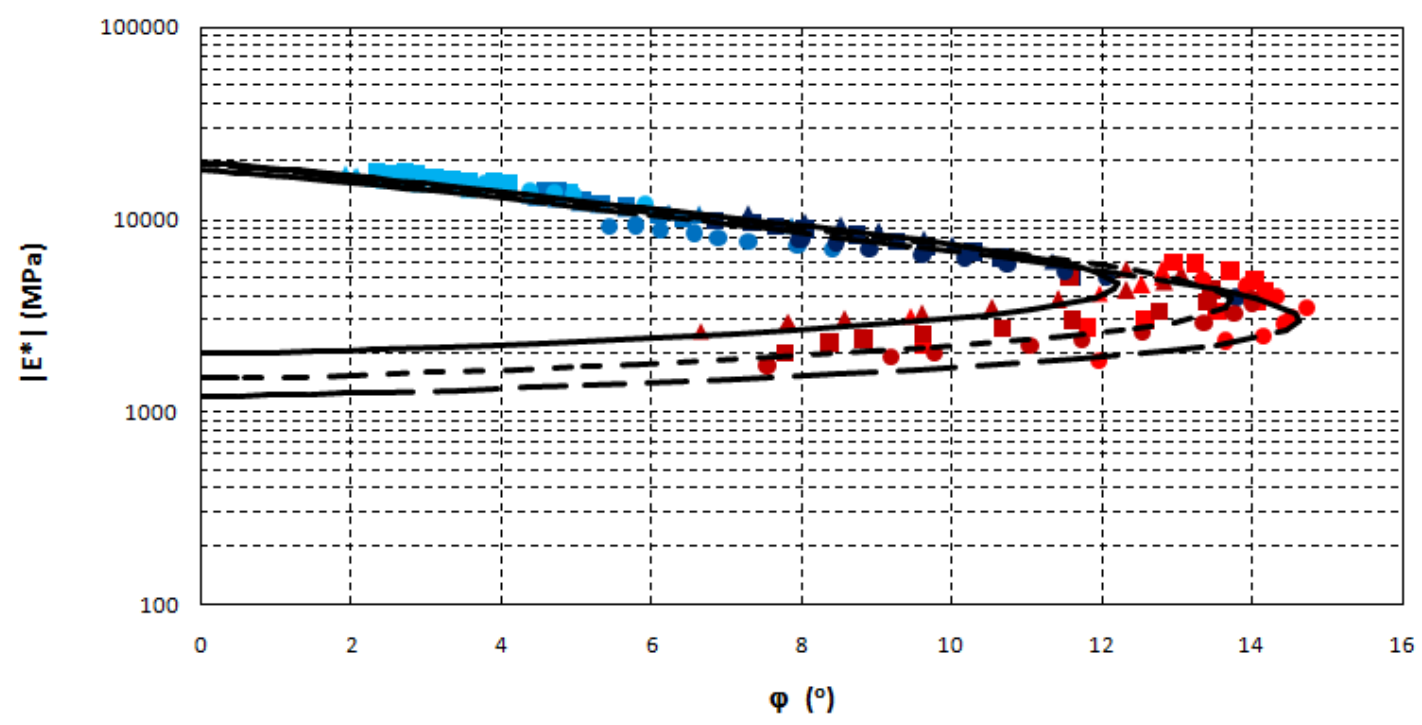
- $\mathrm{TC}=3 \%$
- $\mathrm{TC}=5 \%$
- $\mathrm{TC}=7 \%$

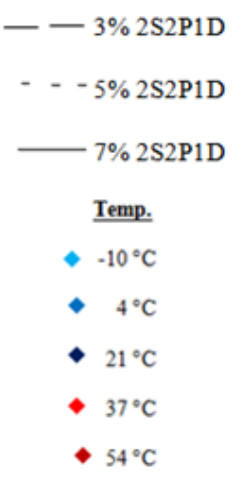

(c)

Figura 6: Diagrama Black: a) $\gamma_{\mathrm{d}}=2,0 \mathrm{~g} / \mathrm{cm}^{3}$; b) $\gamma_{\mathrm{d}}=2,1 \mathrm{~g} / \mathrm{cm}^{3}$; c) $\gamma_{\mathrm{d}}=2,2 \mathrm{~g} / \mathrm{cm}^{3}$ 


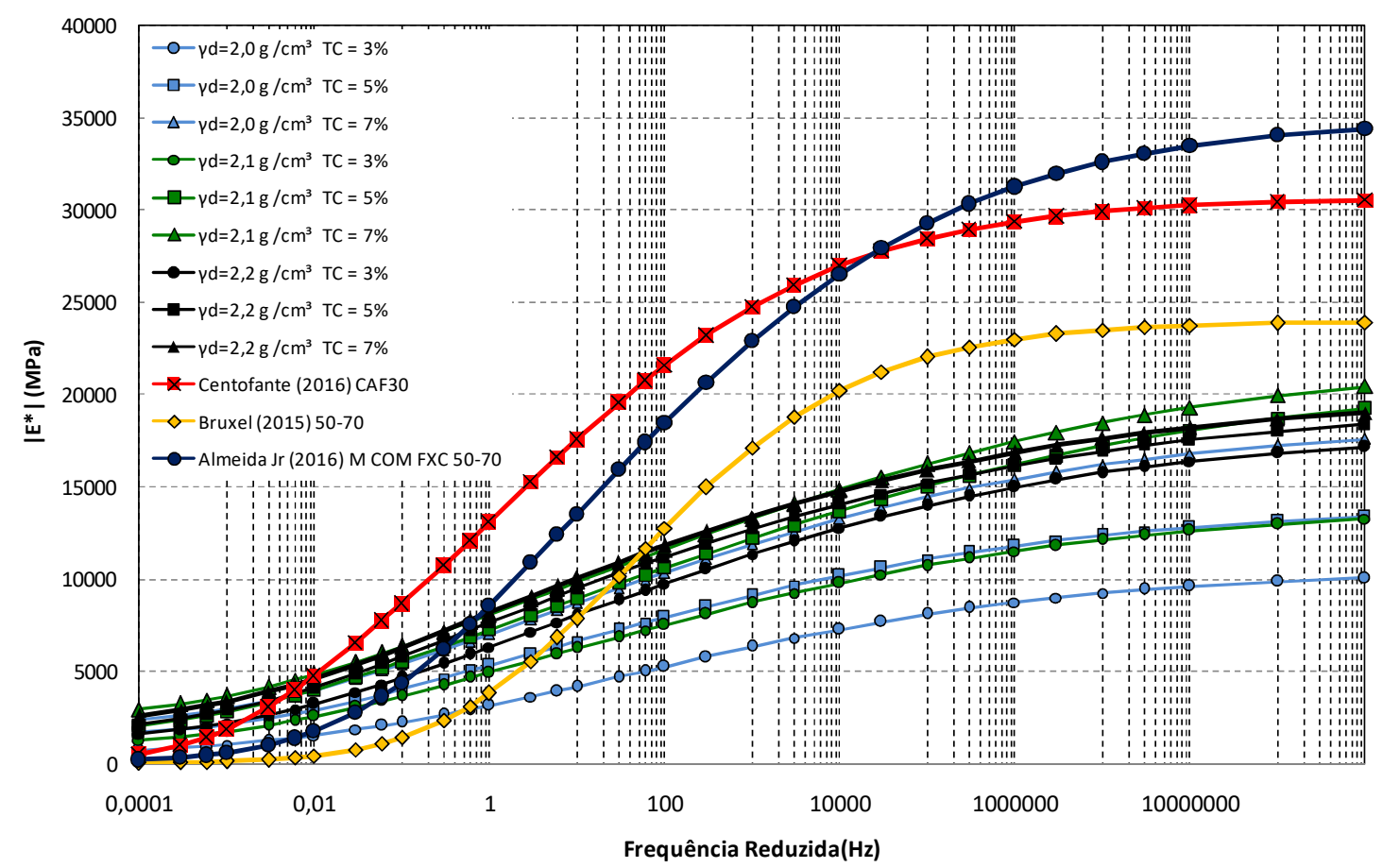

Figura 7: Curva Mestra para os módulos dinâmicos à $21^{\circ} \mathrm{C}$

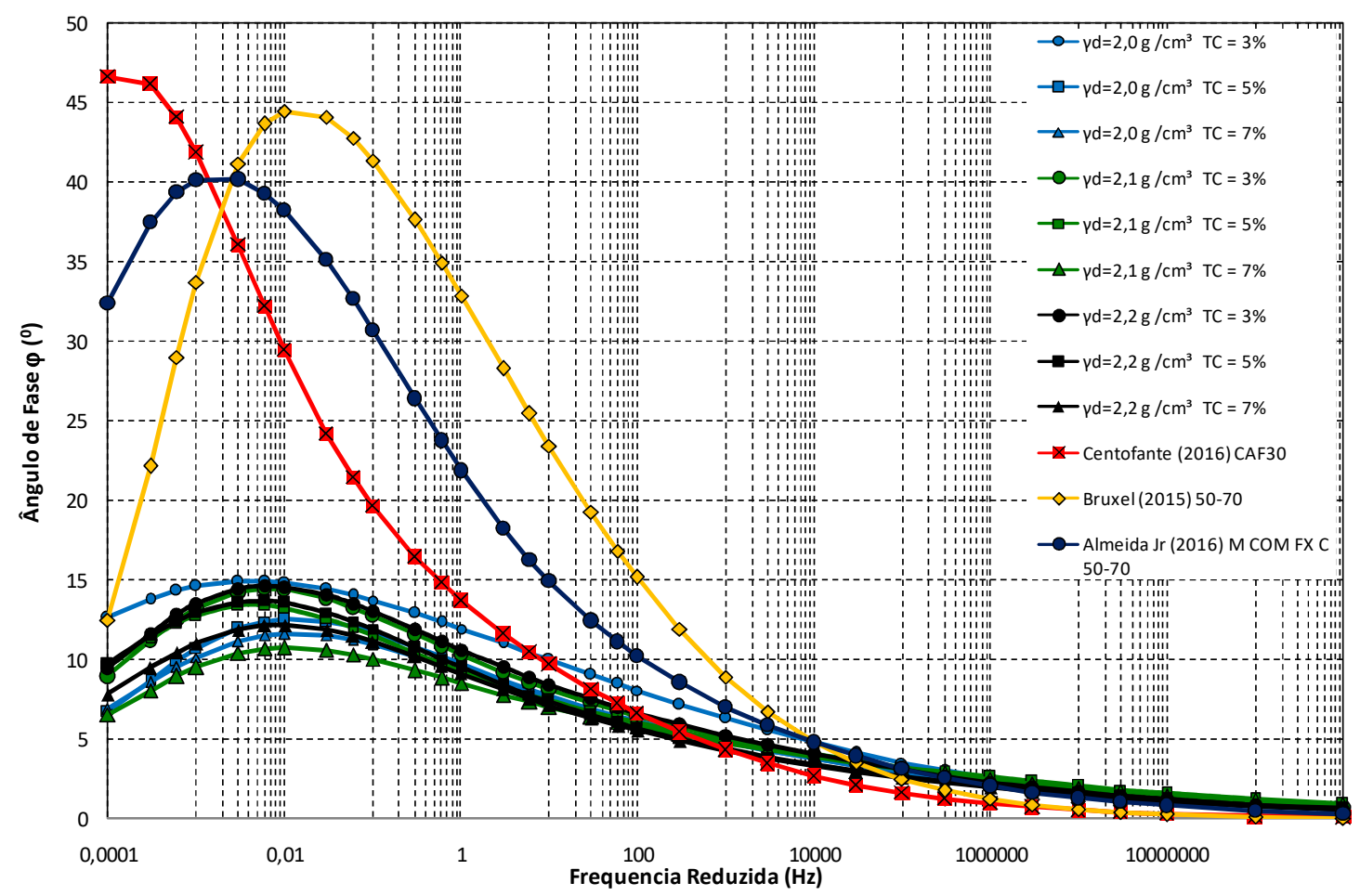

Figura 8: Curva Mestra para os ângulos de fase à $21^{\circ} \mathrm{C}$

\section{CONCLUSÕES}

Podemos perceber o aumento da rigidez nos três teores de cimento estudados (3, 5 e 7\%), e o mesmo

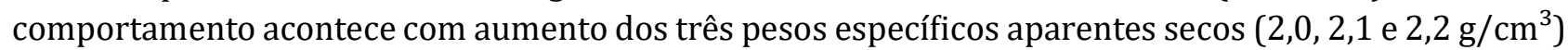
demonstrando assim que o aumento do peso específico gera uma maior rigidez em virtude do fortelecimento do esqueleto mineral, produzida pela aproximação dos grãos, e pode reduzir a adição de cimento. 
Fica claro que para todas as misturas estudadas, há presença de comportamento viscoso, apresentando um ângulo de fase entre $3^{\circ}$ e $14^{\circ}$. Os valores típicos de ângulos de fase de misturas asfáltica variam de $2^{\circ}$ a $50^{\circ}$ considerando a mesma variação de temperaturas e de frequências estudadas. Além disso, os menores valores de ângulo de fase são encontrados quanto maior o teor de cimento, para todos os graus de compactação, em todas as frequências e nas temperaturas mais baixas.

Com a curva mestra das misturas, foi possível verificar que o $\left|\mathrm{E}^{*}\right|$ aumenta em função da frequência. 0 menor valor verificado para o módulo dinâmico é encontrado nas frequências mais baixas, o que explica o formato da curva mestra. Percebe-se, também, importante variação do valor do módulo, e podese afirmar que esta mistura tem propriedades viscoelásticas provenientes da herança do ligante asfáltico presente no material fresado.

Este trabalho mostra que se deve ter cautela ao projetar pavimentos analisando apenas o material como puramente elástico, pois percebemos que há variação do módulo em relação à temperatura e frequências de carregamento. Isso implica que as tensões, as deformações e os deslocamentos na estrutura não serão adequadamente determinados, dificultando a análise mecânica e a aplicação dos conceitos de mecânica de pavimento; cabe, também, a necessidade de calibração de campo que englobe fatores não possíveis de serem modelados (como é o caso de se considerar o material em estudo como elástico).

\section{AGRADECIMENTOS}

Os autores agradecem a Rede Temática de Asfalto / Petrobras / ANP pelo suporte a pesquisa e ao CNPq e CAPES pelas bolsas Pq e de mestrado.

\section{REFERÊNCIAS}

AASHTO (2011) T 342. Determining dynamic modulus of hot-mix asphalt concrete mixtures. Washington, D. C.

AASHTO (2015) TP 79. Standard Method of Test for Determining the Dynamic Modulus and Flow Number for Asphalt Mixtures Using the Asphalt Mixture Performance Tester (AMPT).Washington, DC.

ABEDA (2011). Disponível em < http://www.abeda.org.br/>

ABNT (1991) NBR 5733. Cimento Portland de alta resistência inicial. Rio de Janeiro, RJ.

ABNT (2016) NBR 15619. Determinação da densidade máxima teórica e da massa específica máxima teórica em amostras não compactadas. Rio de Janeiro, RJ.

ABNT (2010) NBR 16018. Misturas asfálticas - Determinação da rigidez por compressão diametral sob carga repetida. Rio de Janeiro, RJ.

ABNT (2001) NBR NM23. Cimento Portland e outros materiais em pó - Determinação da massa específica. Rio de Janeiro, RJ. ABNT (2009a) NBR NM52. Agregado miúdo - Determinação da massa específica e massa específica aparente. Rio de Janeiro, RJ.

ABNT (2009b) NBR NM53. Agregado graúdo - Determinação da massa específica, massa específica aparente e absorção de água. Rio de Janeiro, RJ.

ABNT (2003) NBRNM 248. Agregados - Determinação da composição granulométrica, Rio de Janeiro, RJ.

Almeida Jr.; P. O. B. (2016) Comportamento mecânico de concretos asfálticos com diferentes granulometrias, ligantes e métodos de dosagem. Dissertação (Mestrado em Engenharia Civil). Programa de Pós-Graduação em Engenharia Civil, UFSM Universidade Federal de Santa Maria. Santa Maria.

Araujo, V. M. C.; I. S. Bessa; V. T. F. C. Branco e J. B. Soares (2013). Utilização do processamento digital de imagens para caracterização de material fresado. XXVII Congresso da Associação Nacional de Pesquisa e Ensino em Transportes (ANPET), Belém.

ARRA (1997) Pavement Recycling Guidelines for State and Local Governments Participant's Reference Book. U.S. Department of Transportation, FHWA-SA-98-042. Washington, D.C.

Arulrajah A.; J. Piratheepan e M. M. Disfani (2013) Reclaimed asphalt pavement and recycled concrete aggregate blends in pavement subbases: laboratory and field evaluation. Journal of Materials in Civil Engineering, v. 26, n. 2. DOI:10.1061/(ASCE)MT.1943-5533.0000850

ASTM (2015) D 4123. Standard Test Method for Indirect Tension Test for Resilient Modulus of Bituminous Mixtures. West Conshohocken.

Balbo, J. T. (2007) Pavimentação asfáltica: materiais, projetos e restauração. São Paulo: Oficina de Textos, 558 p.

Bastos, J. B. S.; R. L. Borges; J. B. Soares e L. M. G. Klinsky (2015) Avaliação em laboratório e em campo da deformação permanente de pavimentos asfálticos do Ceará e de São Paulo. Transportes, v. 23, n. 3, p. 44-55. DOI:10.14295/transportes.v23i3.914

Bernucci, L. B.; L. M. G. Motta; J. A. P. Ceratti e J. B. Soares (2010) Pavimentação asfáltica: formação básica para engenheiros. Rio de Janeiro, $504 \mathrm{p}$.

Bessa, I. S.; L. R. Almeida.; K. L. Vasconcelos e L. L. B. Bernucci (2016a) Design of cold recycled mixes with asphalt emulsion and portland cement. Canadian Journal of Civil Engineering, v. 43, n. 9, p. 773-782. DoI: 0.1139/cjce-2016-0111 
Bessa, I. S.; A. L. Aranha; K. L. Vasconcelos; L. L. B. Bernucci; A. H. M. Silva e J. M. Chaves (2014) Caracterização mecânica de misturas asfálticas recicladas a frio. 21ํㅡㄹ Encontro de Asfalto, Rio de Janeiro.

Bessa, I S.; A. L. Aranha; K. L. Vasconcelos; A. H. M. Silva e L. L. B. Bernucci (2016b). Laboratory and field evaluation of recycled unbound layers with cement for use in asphalt pavement rehabilitation. Materials and Structures, v. 49, n. 7, p. 26692680. DOI: 10.1617/s11527-015-0675-6

Bilodeau, K.; C. Sauzéat; H. Di Benedetto; F. Olard e D. Bonneau (2011) Laboratory and in situ investigations of steel fiber reinforced compacted concrete containing reclaimed asphalt pavement. 90th annual meeting of the transportation re-search board, Washington, DC.

Bonfim, V. (2016) Fresagem de Pavimentos Asfálticos. 3 ed., São Paulo: Exceção editorial.

Bruxel, D. F. (2015) Estudo do comportamento viscoelástico de concretos asfálticos convencionais e modificados através de ensaios de laboratório e de análise de desempenho. Dissertação (Mestrado em Engenharia Civil). Programa de Pós-Graduação em Engenharia Civil, UFSM - Universidade Federal de Santa Maria. Santa Maria.

CentofantE, R. (2016) Estudo laboratorial da utilização de material fresado em misturas de reciclagem a quente. Dissertação (Mestrado em Engenharia Civil). Programa de Pós-Graduação em Engenharia Civil, UFSM - Universidade Federal de Santa Maria. Santa Maria.

Christensen, R. M. (1982) Theory of Viscoelasticity. New York: Dover Publications, Inc.

Consoli, N. C.; E. Pasche; L. P. Specht e M. C. Tansky (2017) Key parameters controlling dynamic modulus of crushed reclaimed asphalt paving-powdered rock-Portland cement blends. Road materials and pavement design, v. 4, n. 2, p. 1-18. DOI: $10.1080 / 14680629.2017 .1345779$

Daniel J. S.; N. Gibson; S. Tarbox; A. Copeland e A. Andriescu (2013) Effect of long-term ageing on RAP mixtures: laboratory evaluation of plant-produced mixtures. Road Materials and Pavement Design, v.14, n. 2, p. 173-192. DOI: $10.1080 / 14680629.2013 .812840$

Dalla Rosa, F.; J. F. Silva; L. A. T. Brito e J. A. P. Ceratti (2015) Análise do comportamento mecânico de um pavimento reciclado com adição de diferentes agentes estabilizadores. Transportes, v. 23, n. 2, p. 95-104. DOI: 10.14295/transportes.v23i2.880

Di Benedetto, H.; B. Delaporte; P. Chaverot e G. Gauthier (2004) Linear viscoelastic behavior of bituminous materials: from binders to mixes. Road Materials and Pavements Design, v. 5, n. 1, p. 163-202. DOI : 10.1080/14680629.2004.9689992

Di Benedetto, H. e J. F. Corté (2005) Matériaux routiers. Paris: Hermes-Lavoisier, Paris. 283 p. Vol. 2.

Di Benedetto H. e F. Olard (2003) General 2S2P1D Model and relation between the Linear viscoelastic behaviours of bituminous binders and mixes. Road Materials and Pavement Design, v. 4, n. 2, p. 185-224. DOI: $10.1080 / 14680629.2003 .9689946$

Di Benedetto, H.; M. N. Partl; L. Francken e C. De La Roche (2001) Stiffness testing for bituminous mixtures. Materials and Structures. v. 34, n. 2, p.66-70 DOI: 10.1007/BF02481553

DNER (1994) ME 053.Misturas betuminosas - percentagem de betume, Rio de Janeiro.

DNIT (2006a) Manual de pavimentação. Rio de Janeiro.

DNIT (2006b) Manual de restauração de pavimentos asfálticos. Rio de Janeiro.

DNIT (2010a) ES 141: Pavimentação - Base estabilizada granulometricamente. Rio de Janeiro.

DNIT (2010b) ME 135: Pavimentação asfáltica - Misturas asfálticas -Determinação do módulo de resiliência. Rio de Janeiro.

Dong, Q. e B. Huang (2013). Laboratory evaluation on resilient modulus and rate dependencies of RAP used as unbound base material. Journal of Materials in Civil Engineering, v. 26, n. 2, p 379-383. DOI: 10.1061/(ASCE)MT.1943-5533.0000820

Francken, L. e M. Partl (1996) Complex modulus testing of asphaltic concrete: RILEM Inter laboratory test program. Journal of the Transportation Research Board. v. 1545. DOI: 10.3141/1545-18

Guatimosim, F. V.; K. L. Vasconcelos; L. L. B. e K. Jenkins (2016). Laboratory and field evaluation of cold recycling mixture with foamed asphalt. Road Materials and Pavement Design, v. 19, n. 2, p. 385-399. DOI: 10.1080/14680629.2016.1261726

Hajj, E. Y.; P. E. Sebaaly e R. Shrestha (2009) Laboratory evaluation of mixes containing recycled asphalt pavement (RAP). Road Materials and Pavement Design, v. 10, n. 3, p. 495-517. DOI: 10.1080/14680629.2009.9690211

Hermes, T. B.; J. A. Echeverria e L. P. Specht (2016) Utilização de material fresado como camada de pavimentos em construção de faixa adicional. Revista Pavimentação. v. 41, p. 49 - 62.

Hornych P.; J.M. Balay; C. Mauduit e D. Bodin (2013) Evaluation of the concept of equivalent temperature for pavement design. Ninth International Conference on the Bearing Capacity of Roads, Railways and Airfields. Trondheim, Norway.

Hoyos L.; A. J. Puppala e C. Ordonez (2011) Characterization of cement-fiber-treated reclaimed asphalt pavement aggre-gates: preliminary investigation. Journal of Materials in Civil Engineering, v. 23, n. 7. DOI: 10.1061/(ASCE)MT.19435533.0000267

Hoy M.; S. Horpibulsuk; R. Rachan; A. Chinkulkijniwat e A. Arulrajah (2016a) Recycled asphalt pavement - fly ash geopolymers as a sustainable pavement base material: Strength and toxic leaching investigations. Science of the Total Environment, v. 573. DOI: 10.1016/j.scitotenv.2016.08.078

Hoy M.; S. Horpibulsuk e A. Arulrajah (2016b) Strength development of Recycled Asphalt Pavement - Fly ash geopolymer as a road construction material. Construction and Building Materials, v. 117, p. 209-219. DOI: 10.1016/j.conbuildmat.2016.04.136

Huang, H. Y. (1993) Pavement analysis and design. Englewood Cliffs: Prentice Hall, 805p.

Hunter R. N. (1994) Bituminous mixtures in road construction. London: Thomas Telford. 441p.

Lo Presti D.; N. A. Hassan; G. Airey e A. Collop (2013) Fundamental characterization of reclaimed asphalts: the importance of testing homogeneous specimens. Road Materials and Pavement Design, v.14, n. suplementar 1, p. 120 -131. DOI: $10.1080 / 14680629.2013 .774750$

Lopes, M.; T. Gabet; L. L. B. Bernucci; V. Mouillet e Y. Brosseaud (2015). Incorporacão de Elevado percentual (50\%) de material asfaltico fresado a misturas asfálticas mornas. XVIII Congreso Ibero Latinoamericano del Asfalto, Bariloche. 
Loureiro, T. G.; J. B. SoareS e L. M. G. Motta (2004). Estudo do desempenho de concreto asfáltico com fresado pelo críterio da deformação de tração crítica. 17o Encontro de Asfalto, Rio de Janeiro. p. 308-319.

Mangiafico S.; H. Di Benedetto; C. Sauzéat; F. Olard; S. Pouget S. e L. Planque(2013) Influence of reclaimed asphalt pave-ment content on complex modulus of asphalt binder blends and corresponding mixes: experimental results and model-ing. Road Materials and Pavement Design, v. 14, p.132-148. DOI: 10.1080/14680629.2013.774751

Medina. J. e L. M. G. Motta (2015) Mecânica dos pavimentos. Rio de Janeiro: Editora Interciência, 570p.

Mendes L. O. e G. L. O. Marques (2012) Avaliação da influência do método Bailey no processo de dosagem e desempenho de misturas asfálticas. Transportes, Rio de Janeiro, v. 20, n. 4, p. 35-43. DOI: 10.4237/transportes.v20i4.574

Moreira, J. P. V.; P. Pereira e A. G. Correia (2003) Reutilização de material fresado em camadas estruturais de pavimento. IV Congresso Rodoviário Português - Centro de Congressos do Estoril.

Moreira, H. S. e J. B. Soares (2004). Comparação do comportamento mecânico de misturas asfálticas recicladas a frio com diferentes teores de agregado fresado incorporado. XVII Congresso de Ensino e Pesquisa em Transportes ANPET, Florianópolis. v. 01. p. 01-10.

Nguyen, M. L.; J. M. Balay; H. Di Benedetto; C. Sauzéat; K. Bilodeau; F. Olard; B. Héritier; H. Dumont e D. Bonneau (2016) Evaluation of pavement materials containing RAP aggregates and hydraulic binder for heavy traffic pavement. Road Ma-terials and Pavement Design, v. 18, n. 2, p.264-280. DOI: 10.1080/14680629.2016.1213483

Oliveira, J. A.; V. T. F. C. Branco e J. B. Soares (2013). Avaliação do procedimento de dosagem de misturas asfálticas recicla-das mornas com diferentes percentuais de fresado. XVII Congresso Ibero-Latinoamericano del Asfalto, Guatemala.

Papagiannakis, A. T. e E. A. Massad (2008) Pavement Design and Materials. Hoboken: John Wiley\& Sons. 542p.

Pasche, E.; C. F. C. E. Silva; G. M. Pires; L. P. Specht e J. A. Echeverria (2014). Estudo das características tecnológicas do fresado e suas aplicações em camadas de pavimento no Rio Grande do Sul. 21ํㅡㄹ Encontro do Asfalto, Rio de Janeiro.

Pires, G. M.; L. P. Specht; G. Pinheiro; D. S. Pereira e E. M. Renz (2016) Comportamento mecânico de material fresado após processo de estabilização granulométrica e química por meio da incorporação de cimento e cinza de casca de arroz moída. Matéria, UFRJ, v. 21. DOI: 10.1590/S1517-707620160002.0035.

Puppala A. J.; S. Saride e R. Williammee (2011) Sustainable reuse of limestone quarry fines and RAP in pavement base/subbase layers. Journal of Materials in Civil Engineering, v. 24, n. 4. DOI: 10.1061/(ASCE)MT.1943-5533.0000404

Recasens, J. R. M.; F. E. Pérez-Jiménez e S. C. Aguilar (2000). Mixed recycling with emulsion and cement of asphalt pave-ments: design procedure and improvements achieved. Materials and Structures, v. 33, n. 5, p. 324-330. DOI: 10.1007/BF02479703

Rocha Seg, I.G.; V. T. F. C. Branco; K. L. Vasconcelos e A. S. Holanda (2016) Misturas asfálticas recicladas a quente com in-corporação de elevado percentual de fresado como alternativa para camada de módulo elevado. Transportes, v. 24, n. 4, p. 85-94 DOI: $10.14295 /$ transportes.v24i4.1148

Silva, A. H. M.; L. L. B. Bernucci; S. Ferri; C. Y. Suzuki e J. M. Chaves (2011). Avaliação dos parametros de projetos de restauração pavimentos asfálticos utilizando misturas recicladas com $100 \%$ de agregados fresados. 17a Reunião de Pavi-mentação Urbana, Porto Alegre.

Silva, A. H. M.; K. L. Vasconcelos; A. L. Aranha; L. L. B. Bernucci e J. M. Chaves (2013) Laboratory and Field Evaluation of Coldin-Place RAP Recycling. Transportation Research Board 92nd Annual Meeting, Washington, DC.

Soares, J. B.; L. M. G. Motta e S. A. S. Benevides (2000). Dimensionamento mecanístico de reforço considerando alternativa de base com revestimento fresado incorporado. Simpósio Internacional de Manutenção e Restauração de Pavimentos e Controle Tecnológico, São Paulo.

Soares, J. B.; H. S. Moreira e L. M. G. Motta (2005) Comparação do comportamento mecânico de misturas asfálticas a frio com diferentes teores de fresado incorporado. XIX Congresso de Pesquisa e Ensino em Transportes, ANPET, Recife. v. 2. p. 1283-1293.

Specht, L. P.; N. C. Consoli e J. A. P. Ceratti. (2006). Laboratory study of soil-cement-fiber mixtures under static and repeat-ed loading for pavements. IJP - International Journal of Pavements, v. 5, p. 99-109.

Specht, L. P.; G. M. Pires; T. Vitorello; F. Hirsch; F. Cronst; E. C. Bergmann e M. D. Tiefensee (2013) Utilização de material fresado como camada de pavimento: estudo laboratorial de aplicação em campo. 42 Reunião Anual de Pavimentação - 16 Enacor, Gramado.

Specht, L. P.; L. F. A. L. Babadopulos; H. Di Benedetto; C. Sauzéat e J. B. Soares (2017) Application of the theory of viscoelasticity to evaluate the resilient modulus test in asphalt mixes. Construction and Building Materials, v. 149, p. 648-658. DOI: 10.1016/j.conbuildmat.2017.05.037

Vasconcelos, K. L. e J. B. Soares (2003) Projeto de misturas de concreto betuminosos reciclado a quente com diferentes teores de materiais fresados. XII Congresso Ibero-Latino Americano Del Asfalto, Quito. v. 1, p. 1-10.

Vasconcelos, K. L. e J. B. Soares (2004). Influência do Percentual de Fresado e do Envelhecimento de Curto Prazo na Dos-agem de Misturas Asfálticas Recicladas a Quente. XVII Congresso de Ensino e Pesquisa em Transportes - ANPET, Floria-nópolis. v. 01, p. 01-10.

Wright Jr., F. (2001). FHWA Recycled Materials Policy. Disponível em < http://www.fhwa.dot.gov/legsregs/directives/policy/recmatpolicy.html >

Yoder, E. J. (1959) Principles of Pavement Design. London: John Wiley \& Sons Inc., 569p.

Yoder, E. J. e M. W. Witczak (1975) Principles of Pavement Design. New York: John Wiley \& Sons Inc., ed. 2, 711p.ABEDA (2011). Disponível em < http://www.abeda.org.br/> 